\title{
A rADAR defense against RNAi
}

\author{
Amy E. Pasquinelli \\ Division of Biology, University of California at San Diego, La Jolla, California 92093, USA
}

\begin{abstract}
Adenosine deaminases that act on RNA (ADARs) convert adenosines (A) to inosines (I) in stretches of dsRNA. The biological purpose of these editing events for the vast majority of ADAR substrates is largely unknown. In this issue of Genes \& Development, Reich and colleagues (pp. 271-282) demonstrate that in Caenorhabditis elegans, A-to-I editing in double-stranded regions of protein-coding transcripts protects these RNAs from targeting by the RNAi pathway. Disruption of this safeguard through loss of ADAR activity coupled with enhanced RNAi results in developmental abnormalities and profound changes in gene expression that suggest aberrant induction of an antiviral response. Thus, editing of cellular dsRNA by ADAR helps prevent host RNA silencing and inadvertent antiviral activity.
\end{abstract}

ADAR (adenosine deaminase that acts on RNA) enzymes are found broadly across metazoans and have been estimated to catalyze adenosine (A)-to-inosine (I) editing events in more than half of the human transcriptome (Deffit and Hundley 2016). Since inosine is decoded as guanosine during translation, editing by ADAR in an ORF can result in a change in amino acid sequence and, potentially, protein function. In one of the best-studied examples of this, A-to-I editing of a single position in the mRNA encoding the glutamate receptor subunit causes a glutamine to be replaced with arginine, substantially altering the activity of this protein (Nishikura 2016). However, in most animals, edited sites map to noncoding regions in the transcriptome, including transposons, pseudogenes, long noncoding RNAs, circular RNAs, and the untranslated regions (UTRs) and introns of messenger RNAs (mRNAs) (Deffit and Hundley 2016). The prevalence of these types of ADAR substrates implies that editing must have a purpose beyond recoding protein sequence.

The common feature of all ADAR targets is the requirement for the edited A to reside within a stretch of mostly base-paired RNA. Thus, the conversion of A-to-I in noncoding sequences has the potential to modulate interactions of this region with other factors by either distorting the RNA structure or altering the sequence

[Keywords: self-nonself; RNA editing; siRNA; Dicer; deaminase] Corresponding author: apasquinelli@ucsd.edu

Article is online at http://www.genesdev.org/cgi/doi/10.1101/gad.313049. 118 . identity. For example, editing in introns can impede recognition by splicing machinery, and editing of sequences in $3^{\prime}$ UTRs can impact targeting by the microRNA complex (Deffit and Hundley 2016). One of the first clues that editing prevents the recognition of dsRNA by RNAi factors was the observation that loss of ADAR activity results in transgene silencing in Caenorhabditis elegans (Knight and Bass 2002). It was predicted that the repetitive nature of transgenic arrays produced sense-antisense RNAs that underwent editing by ADARs. In the absence of ADARs, the base-paired RNAs would be vulnerable to cleavage by the dsRNA nuclease Dicer, initiating an RNAi response against the transgenic sequences (Knight and Bass 2002). If editing could protect artificially generated dsRNA from RNAi-mediated silencing, then it seemed likely that the expression of endogenous transcripts with naturally occurring dsRNA stretches might also be regulated by ADARs.

In this issue of Genes \& Development, Reich et al. (2018) demonstrate that hundreds of C. elegans proteincoding transcripts contain editing-enriched regions (EERs), mostly in their introns and UTRs, and loss of ADARs makes these RNAs susceptible to down-regulation by the RNAi pathway (Fig. 1). The EERs are presumably double-stranded, and editing likely masks these structures from being recognized as substrates for Dicer cleavage. Indeed, Reich et al. (2018) identified siRNAs with signatures of Dicer processing that corresponded to most EERs, and levels of these siRNAs increased in worms lacking ADAR activity. The primary siRNAs produced by Dicer can promote the synthesis of secondary siRNAs that further target the originating transcript for down-regulation (Billi et al. 2014). Both primary and secondary siRNAs corresponding to EERs were observed to accumulate in ADAR mutants in an RNAi-dependent manner (Reich et al. 2018). These findings expand on previous reports that ADARs antagonize targeting of various sources of endogenous dsRNA by the RNAi pathway (Wu et al. 2011; Goldstein et al. 2017).

The present study by Reich et al. (2018) also sheds light on the role of ADARs in C. elegans behavior. Loss of ADARs diminishes the ability of worms to migrate

(C) 2018 Pasquinelli This article is distributed exclusively by Cold Spring Harbor Laboratory Press for the first six months after the full-issue publication date (see http://genesdev.cshlp.org/site/misc/terms.xhtml). After six months, it is available under a Creative Commons License (Attribution-NonCommercial 4.0 International), as described at http:// creativecommons.org/licenses/by-nc/4.0/. 


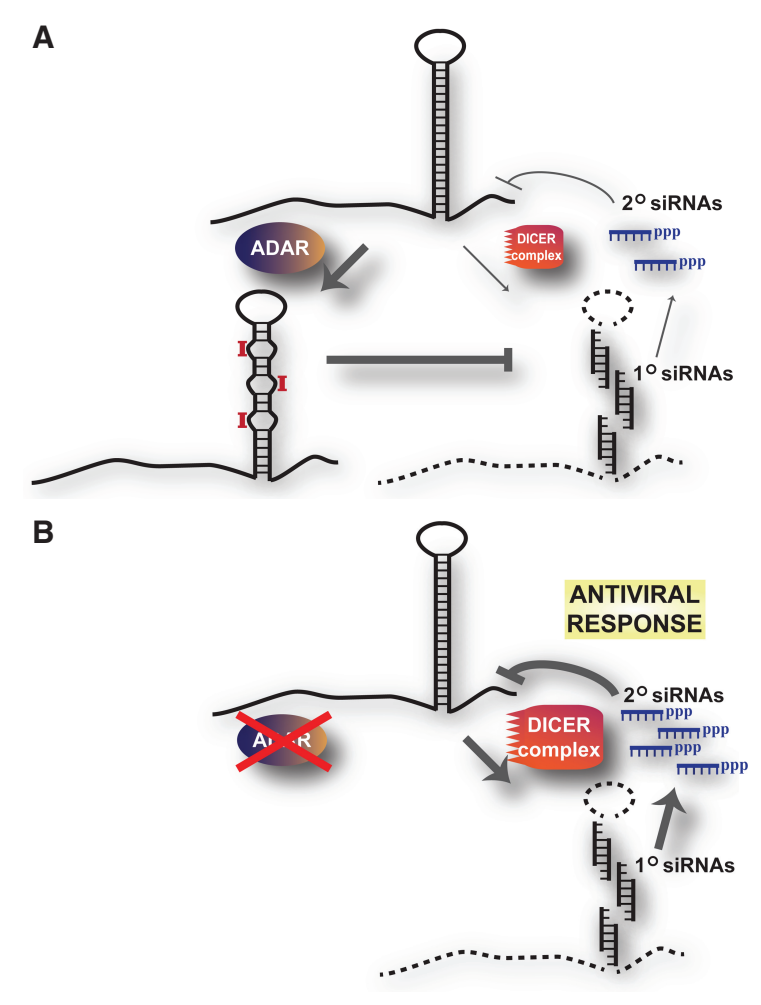

Figure 1. Regulation of dsRNA by ADARs and RNAi. $(A)$ Editing of dsRNA by ADARs prevents recognition by the Dicer complex. (B) Loss of ADARs and increased availability of the Dicer complex results in the cleavage of dsRNA into primary $\left(1^{\circ}\right)$ siRNAs and the generation of secondary $\left(2^{\circ}\right)$ siRNAs that further silence the dsRNA-containing host gene. Aberrant regulation of cellular dsRNA through these pathways triggers an antiviral response in C. elegans.

toward attractive scents (Nishikura 2016). Intriguingly, this chemotaxis defect is rescued by the additional removal of core RNAi factors, suggesting that editing prevents the silencing of genes needed for this olfactory response (Tonkin and Bass 2003). It turns out that misregulation of a single ADAR target, a C-type lectin (clec-41), seems to be responsible for the chemotaxis defect in ADAR mutant worms (Deffit et al. 2017). The Hundley laboratory (Deffit et al. 2017) found that the 3' UTR of clec-41 undergoes editing, and loss of ADAR activity results in decreased neuronal expression of this gene. Moreover, restoration of clec-41 expression in the neurons of ADAR mutant animals rescued the chemotaxis defect. Since Reich et al. (2018) mapped an EER to the clec-41 $3^{\prime}$ UTR and identified increased siRNAs corresponding to this sequence in ADAR mutant animals, editing of this sequence in neurons likely protects clec-41 from RNAi-mediated silencing, a function critical for normal chemosensory behavior in worms.

In contrast to the substantial decrease in clec- 41 mRNA levels in neurons of ADAR mutants (Deffit et al. 2017), Reich et al. (2018) observed that most EER-containing transcripts were only modestly down-regulated in whole worms lacking ADAR activity, suggesting that targeting of them by the RNAi pathway is inefficient. Consistent with this idea, mutations that cause enhanced RNAi by alleviating competition for limiting factors resulted in more robust silencing of unedited EER-associated genes (EAGs). Strikingly, the loss of ADARs combined with an enhanced RNAi background led to prominent developmental abnormalities, and these phenotypes were rescued by removal of core RNAi factors (Reich et al. 2018). Hence, protection of most EAGs by ADAR-mediated editing of double-stranded regions becomes more critical when RNAi factors, such as Dicer, have greater access to these substrates.

Predictably, EAGs were among the $>2000$ genes downregulated in worms deficient in ADAR editing and enhanced for RNAi (Reich et al. 2018). However, just as many genes were found to be up-regulated in this background, including $>50 \%$ of the genes induced by infection with the Orsay RNA virus (Reich et al. 2018). Currently, it is unclear whether the silencing of EAGs indirectly triggers an antiviral response or whether the detection of unprotected dsRNA structures by a heightened RNAi pathway is responsible for the gene expression patterns and developmental abnormalities exhibited by worms lacking ADARs in combination with enhanced RNAi.

Striking parallels for the role of ADARs in preventing dsRNA from triggering inappropriate antiviral programs in worms and immune responses in mammals are now emerging. The loss of ADAR1 causes embryonic lethality in mice because of hyperactivation of the immune system (Bajad et al. 2017). Presumably, unedited endogenous dsRNAs are mistakenly detected as viral invaders by cellular sensors of dsRNA, leading to an overzealous immune signaling cascade. Likewise, the loss of ADARs in C. elegans leaves dsRNA-containing transcripts vulnerable to detection by the RNAi pathway. Additionally, increased availability of certain RNAi factors not only results in stronger silencing of the unedited dsRNA host but also triggers an antiviral response. Thus, editing of dsRNA by ADARs seems to be a conserved mechanism for marking self RNAs to thwart recognition by factors that recognize dsRNA as a sign of invasion.

\section{Acknowledgments}

The Pasquinelli laboratory is funded by grants from the National Institutes of Health through the National Institute of General Medical Sciences (GM071654) and the National Institute on Aging (AG056562).

\section{References}

Bajad P, Jantsch MF, Keegan L, O'Connell M. 2017. A to I editing in disease is not fake news. RNA Biol 14: 1223-1231.

Billi AC, Fischer SE, Kim JK. 2014. Endogenous RNAi pathways in C. elegans. WormBook (ed. The C. elegans Research Community). WormBook doi: 10.1895/wormbook.1.170.1, http:// www.wormbook.org.

Deffit SN, Hundley HA. 2016. To edit or not to edit: regulation of ADAR editing specificity and efficiency. Wiley Interdiscip Rev RNA 7: 113-127. 
Deffit SN, Yee BA, Manning AC, Rajendren S, Vadlamani P, Wheeler EC, Domissy A, Washburn MC, Yeo GW, Hundley HA. 2017. The C. elegans neural editome reveals an ADAR target mRNA required for proper chemotaxis. Elife 6: e28625.

Goldstein B, Agranat-Tamir L, Light D, Ben-Naim Zgayer O, Fishman A, Lamm AT. 2017. A-to-I RNA editing promotes developmental stage-specific gene and lncRNA expression. Genome Res 27: 462-470.

Knight SW, Bass BL. 2002. The role of RNA editing by ADARs in RNAi. Mol Cell 10: 809-817.
Nishikura K. 2016. A-to-I editing of coding and non-coding RNAs by ADARs. Nat Rev Mol Cell Biol 17: 83-96.

Reich DP, Tyc KM, Bass BL. 2018. C. elegans ADARs antagonize silencing of cellular dsRNAs by the antiviral RNA interference pathway. Genes Dev (this issue). doi: 10.1101/ gad.310672.117.

Tonkin LA, Bass BL. 2003. Mutations in RNAi rescue aberrant chemotaxis of ADAR mutants. Science 302: 1725.

Wu D, Lamm AT, Fire AZ. 2011. Competition between ADAR and RNAi pathways for an extensive class of RNA targets. Nat Struct Mol Biol 18: 1094-1101. 


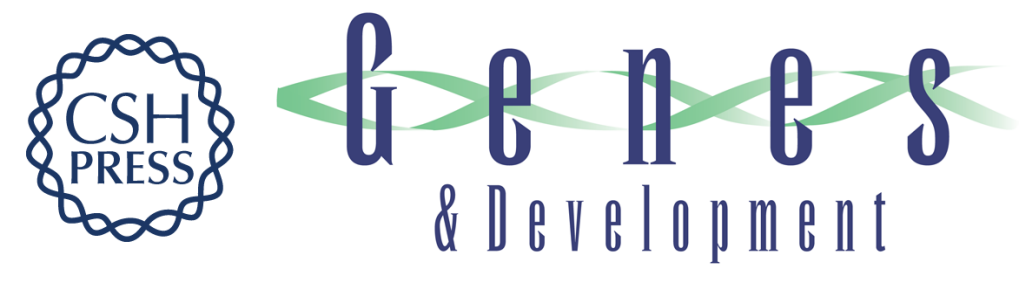

\section{A rADAR defense against RNAi}

Amy E. Pasquinelli

Genes Dev. 2018, 32:

Access the most recent version at doi:10.1101/gad.313049.118

Related Content C. elegans ADARs antagonize silencing of cellular dsRNAs by the antiviral RNAi pathway

Daniel P. Reich, Katarzyna M. Tyc and Brenda L. Bass

Genes Dev. February , 2018 32: 271-282

References This article cites 10 articles, 3 of which can be accessed free at:

http://genesdev.cshlp.org/content/32/3-4/199.full.html\#ref-list-1

Articles cited in:

http://genesdev.cshlp.org/content/32/3-4/199.full.html\#related-urls

Creative This article is distributed exclusively by Cold Spring Harbor Laboratory Press for the first Commons License six months after the full-issue publication date (see http://genesdev.cshlp.org/site/misc/terms.xhtml). After six months, it is available under a Creative Commons License (Attribution-NonCommercial 4.0 International), as described at http://creativecommons.org/licenses/by-nc/4.0/.

Email Alerting Receive free email alerts when new articles cite this article - sign up in the box at the top Service right corner of the article or click here.

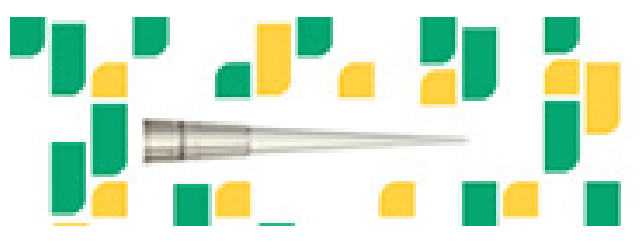

Focused on your science. 